\title{
Filme em debate: Ondjaki fala de sua obra Oxalá cresçam pitangas
}

\author{
Paula Faccini de Bastos Cruz*
}

Neste artigo interpretamos a palestra ministrada por Ondjaki, escritor e cineasta angolano, e seguida de debate, ocorrida no dia 21 de novembro de 2011, após a apresentação do filme Oxalá cresçam pitangas - histórias de Luanda (2006), produzido e realizado por este e Kiluanje Liberdade. ${ }^{1} \mathrm{Na}$ ocasião, a palestra e o debate foram devidamente gravados. O evento, organizado pelo Cineclube do Laboratório de Estudos Africanos, do Instituto de História da Universidade Federal do Rio de Janeiro (Afrocine/LeÁfrica/ IH/UFRJ), foi aberto ao público em geral, porém contou com a presença de graduandos e pós-graduandos, assim como com professores de diversas disciplinas e de diferentes instituições, tornando o diálogo mais acadêmico.

A transcrição foi feita, inicialmente, a partir do material gravado, com o rigor de não se deixar perder nada daquilo que pudesse ser compreendido nos silêncios, ênfases ou reticências, e para tanto foram usados recursos gráficos, como o negrito, itálico ou parênteses. A seguir, já transcrito, o texto foi enviado para o autor, para que este pudesse retificar aquilo que sentisse necessidade, assim como autorizasse a sua utilização em nossa atual investigação (Tourtier-Bonazzi, 1996, p. 239-240). Este primeiro resultado, mantido na íntegra, fará parte de um arquivo produzido a partir dos eventos

* Doutoranda Capes no Programa de Pós Graduação em História Comparada da Universidade Federal do Rio de Janeiro (PPGHC/UFRJ).

1 Kiluanje Liberdade nasceu em Angola, em 1976. Licenciado em Ciências da Comunicação e Cultura na Universidade de Lisboa, fez pós-graduação em Estudos Africanos (ISCTE, Lisboa), e é atualmente um dos maiores expoentes do cinema angolano. 
similares que se seguirão a este, com a continuidade das atividades do Afrocine. Nosso escopo geral é criar um banco de dados, de fontes de pesquisa que historiadores, cineastas e outros profissionais dessa área de interesse possam também acessar.

Nosso objetivo particular, através da elaboração desta nova fonte primária, foi alargar as dimensões de nosso objeto de estudo. A propósito, gostaríamos de elucidar nossa pesquisa: analisamos alguns elementos que estão construindo e afirmando identidades em Angola, sejam eles étnicos, ocidentais, atuais ou coloniais, através do estudo do cinema produzido nesse país. Pudemos encontrar esses fatores principalmente nos filmes produzidos pela chamada Segunda Geração ${ }^{2}$ de cineastas angolanos, estes jovens e talentosos produtores, que com alguma ajuda do Estado e muita vontade e esforço próprio vêm marcando o atual momento social, político e estético da produção cinematográfica de Angola. Ondjaki e Kiluanje Liberdade, realizadores do filme em questão, fazem parte desse grupo. Diz o primeiro:

O filme foi produzido em 2005, com algumas limitações técnicas, mas com muita vontade humana: nossa, da equipa, e das pessoas - tivemos muita ajuda em Luanda. Pessoas emprestaram o apartamento, a casa, carro, comida, gasolina. Fizemos o filme com alguma dificuldade, mas com muito boa vontade - das pessoas em Portugal também. Fizemos Angola/Portugal, porque muita gente de Portugal nos ajudou, sobretudo na fase de pós-produção. Ajudar, como vocês sabem, num filme como este, é trabalhar sem receber dinheiro, praticamente era esse o modo.

Oxalá cresçam pitangas - histórias de Luanda é um documentário que busca mostrar a vida dos jovens na complexa cidade de Luanda, após tantos anos de guerra. Os produtores escolheram dez personagens, através dos quais o público entra em contato com as diferenças e semelhanças entre eles, as suas dificuldades e, mais do que isso, sua busca por identidade e resiliência: uma força capaz de fazer renascer e seguir adiante - oxalá!

Perguntado acerca do nome do filme, o autor afirmou ter extraído o título de um poema, quando estava fazendo uma pesquisa de poesia. Sua

2 A decisão de alienar completamente a produção de cinema ao setor privado marcou um segundo momento na história do cinema angolano. Os cineastas surgidos após esse período formam um grupo identificado como Segunda Geração. 
ideia inicial era fazer um filme híbrido de documentário com ficção, e por isso preparava poemas para serem lidos durante o filme. Depois, junto com Kiluanje, ficou decidido que fariam um filme mais documentário, mas ele já tinha se encantado pela frase do poema, que dizia assim: "Oxalá cresçam pitangas no papel”. Ondjaki mostrou-a a Kiluanje, sugerindo que tirassem "no papel", ficando apenas "oxalá cresçam pitangas". A essa altura ainda não tinham sequer conversado sobre o filme, nem como iam filmar, mas o título ia ser esse. Agora o porquê dessa escolha, com bom poeta que é, deixou para cada um chegar à própria conclusão. Esclarece apenas que pitanga não é uma fruta que tenha nenhum significado específico em Luanda.

O cinema angolano pode ser entendido por fases distintas, dividido por épocas, com características próprias cada uma delas. A maior diferença entre o cinema produzido quando da independência do país e o que é feito hoje é a maior liberdade no sentido temático e criativo das produções. No entanto existe muita disparidade entre estas últimas obras, tanto em relação aos meios de produção quanto qualitativamente. Inferimos que na maioria dos casos uma coisa é consequência da outra. Ondjaki sublinha também a importância dos festivais de cinema africanos para o desenvolvimento da sétima arte no continente. E cita como exemplo o Festival Internacional de Cinema de Luanda (FicLuanda).

A questão geracional no cinema angolano é interessante. Houve coisas muito importantes filmadas pelo Ruy Duarte de Carvalho, ${ }^{3}$ como Presente angolano, tempo mumuila, ${ }^{4}$ e outros desta geração. Depois há um período em que quase ninguém filma. Então aparece a Joanita, a Maria João Ganga, ${ }^{5}$ que está desde 1991 com aquele roteiro, $\mathrm{Na}$ cidade vazia, mas ela só vai filmar em fevereiro de 2004. Depois filma o Zezé Gamboa, ${ }^{6}$ também

3 Escritor, cineasta e antropólogo angolano, Carvalho é uma referência como documentarista do primeiro momento do cinema em Angola.

4 Série de documentários etnográficos produzida por Carvalho, que tinha como objetivo refletir sobre o progresso e a cultura da sociedade angolana. Tornou-se um marco de sua época.

5 Ganga nasceu em Huambo, Angola, em 1964, e estudou cinema na L'école Superieure d'Etudes Cinematographiques Libres (ESEC), Paris.

6 Gamboa estudou no Liceu Salvador Correia, em Luanda, e começou seu trabalho na extinta RTPA (Rádio Televisão Popular de Angola) em 1974, aos 17 anos. Sua obra mais importante é o filme $O$ herói, vencedor do Sundance Festival para melhor filme estrangeiro, em 2008. 
com um roteiro muito antigo, e é produzido $O$ comboio da Canhoca, ${ }^{7}$ do Orlando Fortunato. ${ }^{8}$ E por último surgem os miúdos, que somos nós, a tentar fazer uma coisinha ou outra com esses meios que temos. Mas recentemente, nos últimos três, quatro anos, inclusive com o surgimento do Festival Internacional do Cinema de Luanda, tem havido alguns incentivos. É preciso estar por perto, e dizer "olha estou a filmar em março, e talvez o filme esteja pronto pra novembro". Então você se apresenta no festival. Isto está a acontecer. Agora, existe um circuito paralelo, como o Dito, ${ }^{9}$ que está a filmar Assalto em Luanda, Assalto em Luanda II, III, ${ }^{10}$ é um gênio, não sei. Há uns outros que filmam nos bairros, com câmeras muito mais precárias, com limitações técnicas, mas que têm ideia estruturada e vale a pena ver, pra conhecer! E tem o Mario Bastos, um rapaz que fez agora um curta chamado Alambamento. ${ }^{11}$ Ele fez cinema nos EUA e tal, mas está muito atento a tudo e ajuda, partilha seu material e está a trabalhar com os outros. E quem é o diretor, o realizador é o Kiluange!

Procuramos precisar o lugar de produção da obra, ou seja, quem a elaborou, a partir de qual estrato social, envolvimento intelectual, estético e político dentro da sociedade angolana, com o intuito de compreender a subjetividade do discurso do filme em questão; enxergar através da lente que captou aquelas imagens, apreender suas escolhas, seus significados. Por intermédio dessa nossa fonte oral tivemos naturalmente mais informações sobre nosso palestrante do que sobre Kiluanje Liberdade. Ondjaki é poeta e literato, além de cineasta. Nascido em Luanda, em 1977, após a independência, cresceu durante as guerras que se seguiram. Seus primeiros anos de estudo foram em

7 O filme, rodado em 1989, narra uma história, ambientada em 1957, de 19 presos políticos que viajam num vagão fechado, rumo a Luanda, e que fica retido por três dias na estação de Canhoca. Por razões políticas o filme não foi mostrado por mais de 15 anos.

8 Natural da cidade de Benguela (Angola), em 1946, Fortunato é formado em ciências geofísicas. Começou a realizar filmes em 1970, quando dirigiu $O$ mamadou 24. É um dos pioneiros do cinema de seu país.

9 Dito formou-se na área de ficção pela Televisão Pública de Angola (TPA), e também na escola de cinema de Mahol, na França.

10 A trilogia Assaltos em Luanda (2007, 2009 e 2011, respectivamente) é de filmes de ação e ficção, onde o autor, através de seu olhar, pretende trazer ao público histórias do quotidiano da cidade, particularmente das zonas onde o cidadão vive em constante insegurança devido ao alto índice de criminalidade.

11 Mário Bastos mudou-se aos 16 anos para Nova Iorque, onde frequentou a E. F. Internacional Language School. Em 2006 formou-se na New York Film Academy (NYFA), no curso técnico de realização. Esse curta conta a história do dia de entrega do alambamento (pedido de casamento) por Matias ao pai da sua namorada. 
sua terra natal, e no liceu teve como mestre alguns professores cubanos, tendo criado grande admiração e afeição por um deles, o que influenciou muito sua formação: "Há umas coisas que aprendemos em Angola, nos anos $1980 \mathrm{em}$ relação ao bem coletivo, e que alguns interiorizaram. E outros não interiorizaram!" Ao terminar o ensino básico, mudou-se para Lisboa, onde se formou em sociologia. Porém Ondjaki não se considera sociólogo: "Às vezes as pessoas pensam que eu sou sociólogo, porque fiz licenciatura em sociologia, mas não entendo nada de sociologia. Já estou como Manoel de Barros, cada vez entendo menos sobre quase tudo!" No entanto percebemos na estrutura e na clareza de seu pensamento, assim como em sua obra, o somatório de toda essa formação. Como, por exemplo, quando fala da educação:

[...] quanto ao ensino, está-se a construir muitas faculdades, muitas escolas, o que é bom. Escolas bonitas, belos prédios, com tudo mais. Mas, quero dizer, é preciso preocuparmo-nos com a qualidade destes professores, não é? Que estão nessas escolas! Não bastam prédios novos. Mas eu sou uma pessoa otimista, quero sempre pensar que nós vamos conseguir, que nós só estamos a começar. Veja, é um país que é independente há 36 anos, mas cuja guerra acabou há nove anos! Portanto, a gente exige, quer que o governo faça o melhor, obviamente. Mas também é preciso contextualizar as coisas [...].

Foi nos Estados Unidos, onde viveu durante seis meses, que Ondjaki estudou cinema, tendo voltado depois para Angola. Afirma ter feito o documentário porque queria dizer algumas coisas nesse formato, porém não se sente um cineasta propriamente. Podemos também perceber o envolvimento intelectual e político do diretor, quando ele justifica a escolha do ângulo da cidade, aquilo que dela quis mostrar:

E quando as pessoas reclamam dessa Luanda que fui mostrar, eu digo: mas, essa Luanda, qual? Esta é a Luanda que existe! Há um núcleo de pessoas, uma minoria, que vive numa outra Luanda, muito bem, e existe a Luanda mais real. Há uns que não querem ver isto, e há outros que não veem, pura e simplesmente!

Esta questão da escolha das locações também se deveu muito às condições materiais, que impuseram uma série de limitações, segundo seu depoimento. Essa opção se desenhou de forma definitiva na ilha de edição, pois 
foram apenas 27 dias de filmagem, que resultaram em 42 horas de material gravado e em uma hora de película montada, na versão final. As pessoas escolhidas eram conhecidas dos diretores, e essas foram trazendo outras pessoas. É evidente que existia uma intenção inicial de mostrar a cidade em sua diversidade, buscando retratar a maioria de sua população, no que ele chamou de "a Luanda mais real". Existem lugares da cidade, naturalmente, como as praias e as discotecas, que não foram mostradas. Mas segundo Ondjaki, a parte da sociedade que frequenta esses lugares é uma minoria riquíssima, e não era esse o universo que os interessava. Portanto, foi uma visão de Luanda resultante do acaso, de limitações materiais, mas certamente também de escolhas.

Outra coisa muito presente em seu filme, porém na maior parte do tempo de forma implícita, é o passado de guerras. A paz é muito recente em seu país, e por esse motivo sentimos essa intensa presença no filme, através das histórias de vida de seus personagens.

O processo da guerra em Angola é um processo longo e complicado, é uma acumulação de várias guerras. Há uma primeira guerra, um primeiro momento de guerra, contra a ocupação colonial portuguesa. A independência de Angola é uma coisa recente, data de 1975. Logo a seguir há o envolvimento de muitas forças internacionais, sobretudo sul-africanas, cubanas, russas, americanas, a CIA. A partir de 1992 a guerra torna-se mais nacional, basicamente entre o MPLA e a UNITA, mas ainda com interferências de alguns mercenários. Portanto, em Luanda a guerra não é uma coisa extremamente presente, isto é, a guerra em si, os bombardeamentos. O que era presente em Luanda, além das consequências naturais - falta d'água, falta de luz - foi um grande êxodo rural. As pessoas abandonaram seus locais de origem e vieram viver em Luanda, junto dos seus familiares, justamente porque Luanda era um sítio seguro, relativamente seguro, em comparação com outras províncias, como o Bié, a Lunda, o Cuando, o Cubango. Portanto é natural que, não tendo sido bombardeada no sentido literal, Luanda tenha essa vivência de acumulação de pessoas, como um manto de retalhos. Você vai a Luanda e encontra vários bairros: bairros mais misturados, e bairros específicos, com gente do sul, do Uíge, de Cabinda. Luanda é isso, é essa mistura. Por isso é que, por exemplo, na literatura, é quase impossível haver um livro, mesmo que de poesia, sem uma referência implícita ou explícita ao processo de guerra. [...] Muitas daquelas pessoas que vemos no filme viveram a guerra. Aquele rapaz, o Francisco, que conta 
como saiu de uma zona de guerra e chegou a Luanda. Ele viveu alguns anos na rua, e hoje ele é uma pessoa que está no segundo ano da faculdade. Isso não acontece com toda gente, não é? Mas é uma pessoa, por exemplo, que tem a guerra como fator endógeno. Hoje ele é um cidadão de Luanda, mas a guerra mudou completamente a vida dele.

Percebemos que as principais características da cidade, como a pluralidade étnica, a ocupação desordenada, a falta de infraestrutura, como transportes, saneamento básico, a má distribuição da população, foram também resultantes da guerra. Em sua palestra nosso orador estimou a população de Luanda atualmente em sete milhões de habitantes, um terço da população do país. E, segundo ele, Luanda é uma cidade pequena, seu centro financeiro não comporta tanta gente. Apesar de considerar o grande número de habitantes por metro quadrado problemático, percebe que isso também gera festa, dinâmica cultural, contato entre as pessoas. Este lado positivo está presente tanto em seu discurso quanto em sua obra.

Ondjaki nos relata o esforço do governo de minimizar alguns problemas, criando soluções alternativas que, no entanto, não alcançaram o resultado esperado. Como é o caso da habitação, onde este ano foi criado um programa para a construção de uma nova cidade. Mas não ficou claro para a população o que é preciso fazer para conseguir uma casa lá. Disseram-lhe que é preciso negociá-las com determinada empresa, a preços absurdos. Um apartamento estaria custando em torno de 125 mil dólares, preço que uma pessoa de classe média alta, em Luanda hoje, pode conseguir. Mas a maioria da população não pode comprar um apartamento nesse valor. Ora, se a intenção era fazer uma cidade onde os apartamentos fossem baratos, para resolver o problema de moradia, esse objetivo não foi atingido. A construção é chamada de cidade, porque vai comportar mais de 300 mil casas, mas não é projetada como uma cidade, e sim como um imenso bairro. E não há sequer um financiamento do governo, os interessados precisam negociar direto com os bancos, que fazem muitas exigências. São tantas que somente aqueles que possuem um emprego com algum tipo de comprovação conseguem. No entanto a grande maioria da população da cidade sobrevive da chamada economia informal. São essas pessoas que vivem da venda de diversos produtos na rua, e que muitas vezes conseguem ganhar regularmente seu dinheiro, mas não possuem uma comprovação de renda, exigência mínima na hora de pedir empréstimo ao banco. 
A informalidade está presente por todos os cantos da cidade, e aparece no filme, evidentemente. Sobre este aspecto econômico, o diretor se posicionou, afirmando que

há, às vezes, uma visão, como se tivesse havido um grande boom, originando uma grande economia informal. Eu, pessoalmente, penso ao contrário. É preciso parar de pensar nesta economia como sendo informal. Ou seja, tem que haver uma maneira de formalizar estas práticas econômicas, que na realidade são a maioria. Do ponto de vista oficial, quem está trabalhando numa empresa está no mercado formal, quem está na rua a vender nos panos e zongar ${ }^{12}$ está no informal. Mas esta senhora zongueira, que vende comida na rua, educa seus filhos, procura ganhar dinheiro para as crianças estudarem.

No seu entender esse fenômeno econômico é resultado da reconstrução nacional, fundamental após tantos anos de guerra. Houve a necessidade de uma reconstrução física, propriamente dita: pontes, estradas, prédios, escolas e hospitais, o que terminou gerando aquilo que ele chamou de "um grande boom", que criou uma série de novas oportunidades, trazendo inclusive muitos investidores de fora. Porém gerou também uma especulação de preços enorme no setor de arrendamento e compra de casas. Ondjaki não identifica esse fenômeno como sendo exclusivo de Angola, mas comum a todo o continente africano. "A vida do continente é uma vida feita de economias paralelas. Nós temos que arranjar uma maneira de inserir isso no mundo da economia nacional". A seguir dá o exemplo de países que conseguiram solucionar esse tipo de problema, como a Suécia e a Suíça, quando incluíram a prostituição no esquema oficial, criando planos de saúde para aquelas pessoas, reconhecendo legalmente sua profissão.

Eu penso que em África terá de haver também uma tentativa de criar um mecanismo para que estas pessoas, que aparentemente estão no informal, passem pra uma formalidade. Não é só chegar lá e acabar com os mercados. Os mercados existem porque o público precisa deles, senão deixariam de existir.

Essa acumulação de pessoas vindas de todas as regióes de Angola, esse "manto de retalhos", como disse o cineasta, fez com que Luanda fosse

12 Vender na rua, sem autorização, de forma extraoficial. 
assumindo características específicas, através das quais o luandense se identifica, como é o caso do uso da língua portuguesa. Ondjaki vive na cidade do Rio de Janeiro há três anos, e esse distanciamento o permitiu perceber de forma mais apurada esse fenômeno. Porque apesar de ambos os países serem lusófonos - Brasil e Angola, a experiência que se tem da língua é muito diferente. Ele afirma que em Luanda há uma vivência teatral e inventiva da língua, como se através dela as pessoas manifestassem sua necessidade de criar. Lá todas as semanas surgem novas músicas, por exemplo, num processo que começa, às vezes, quando alguém usa um calão novo, um tema, que pode ter derivado de uma novela brasileira, ou de um termo em inglês. Ou de um erro ou acidente, que origina uma estória. E qualquer estória origina novas palavras.

Estas novas palavras vão aparecer em pelo menos em três componentes em Luanda: na música, através do rap e do kuduro; nas estigas, que é uma coisa muito difícil de explicar - estigas é um jogo de ofensas, é mais praticado entre as crianças; e também, às vezes, no discurso oficial. É interessante porque às vezes as palavras que estão na música, que estão a vivenciar, digamos, o lado mais social, coloquial de Luanda, são incorporadas depois pelo lado político. O locutor do rádio já a incorpora. É uma vivência natural.

Essa especificidade criativa do uso da linguagem entre os luandenses é tão comum que não lhes causa estranhamento. As pessoas não questionam se a palavra usada existe, se é assim que costumam falar em determinado lugar ou grupo. "Não há uma necessidade de se justificar se é de onde, de que grupo! É uma coisa pessoal. Só que lá é pessoal de sete milhões!” A essa qualidade da língua portuguesa falada em Luanda somam-se as palavras vindas do quimbundo, do umbundo, do utchkwe, etc. "É uma vivência linguística muito, muito rica e muito bonita. Há coisas que são culturais, às vezes não dá sequer para traduzir." Essa teatralidade aprende-se desde a mais tenra infância, nos jogos de estigar. É uma brincadeira muito comum em Luanda, pratica-se nas ruas e escolas, apesar de já estar perdendo espaço por causa dos jogos eletrônicos. Com cinco, seis anos as crianças começam com esta disputa oral. Um joga contra o outro. Não existem rimas, são pequenas histórias. Normalmente ofende-se a família, o pai, o irmão, tomando-se cuidado para não envolver a mãe. Mas no decorrer do jogo, às vezes entra também a mãe. O palestrante dá um exemplo de como o jogo inicia: “'Na tua casa 
puseram o rádio na geleira pra ouvir notícias frescas.' A pessoa é estúpida, pôr o rádio dentro da geladeira para ouvir notícias frescas! [...] depois metem a mãe, metem a irmã, metem os transexuais." As crianças costumam praticar até os 11, 12 anos, quando param de jogar. Mas essa criança que esteve dos 5 até os 12 anos praticando esse jogo tem um treino mental, uma rapidez, uma criatividade, uma improvisação impressionantes, e algumas vão levar isto para o rap. Segundo o diretor, os rappers que aparecem no filme cresceram nesse ambiente de estigas, e eram todos muito bons. Aponta MCK como um dos maiores rappers de Angola. Estes rapazes às vezes se encontram em Portugal, e se juntam, formando um conjunto chamado Ngonguenha ${ }^{13}$ que, segundo Ondjaki, faz um rap satírico, humorístico, cômico. E em uma de suas músicas, $E$ dreda ${ }^{14}$ ser angolano, eles vão brincar com outra característica dos luandenses.

Ele está a autoironizar: é dreda ser angolano! Porque ele está a brincar com uma coisa absurda que os luandenses fazem [...]. Primeiro eles acham que são os melhores do mundo, depois, eles acham que são os melhores de Angola, depois eles são os melhores do bairro, os melhores da rua, etc. E eles brincam com isso, quer dizer, é dreda ser angolano. Ele diz que os luandenses atraem as miúdas da África do Sul, apesar do cheiro ao lixo que temos aqui na banda - na banda é Luanda! A banda não é a banda de tocar, a banda é a cidade de Luanda.

Durante a projeção vemos imagens de crianças jogando basquete. Perguntado pelo esporte, nosso palestrante esclareceu que Angola está fortemente representada, sobretudo a nível continental, no handebol feminino e no basquetebol masculino. Pratica-se também o hóquei com patins e a natação. Os jovens jogam nas ruas o basquete, e de fato existem muitas tabelas na cidade de Luanda, provavelmente por ser mais fácil de jogar do que o futebol, onde é preciso mais espaço, um campinho que seja. O basquete se tornou uma paixão muito forte em Angola, que foi campeã africana por dez vezes, sendo sete consecutivas. E ele brinca: "Fizeram uma carta oficial às Nações Unidas para pedir para Angola não ir todos os anos ao campeonato de basquetebol africano, porque aquilo já estava a ficar sem graça! Sete vezes

13 Comida típica de Luanda, normalmente servida no lanche das crianças.

14 "É dreda": é o máximo, é ser o melhor. 
consecutivas! Então pediram para criar um estatuto especial e Angola só ir ano sim, ano não."

Outra característica da sociedade luandense, também consequente das especificidades de sua formação em função das guerras, de ter se tornado tão plural, são os casamentos.

No filme aparecem duas referências, mas, segundo o cineasta, há casamentos de todos os tipos. Alguns mais ocidentalizados, com os homens vestindo terno e gravata, e outros onde as pessoas vestem panos tradicionais. Varia de família para família, de pessoa para pessoa, dependendo menos da capacidade financeira do casamento e mais de uma opção estética. Existem casamentos misturados, com pessoas com panos e pessoas de terno e gravata, e mulheres com vestidos caríssimos. "Sabe, Luanda é um meio urbano muito misturado, muito misturado." E tudo aquilo que envolve um casamento, as diversas cerimônias, são muito bonitas. Como, por exemplo, o pedido de casamento. "Ver uma cerimônia do noivo a ir pedir a noiva é uma maravilha, seja em que ambiente for! Dava para fazer um outro filme!” Nesse momento da palestra nosso literato póe-se à frente do cineasta, e inicia a narrativa de uma cerimônia dessas, que infelizmente não poderemos reproduzir aqui por falta de espaço, mas que é impagável, realmente uma festa. Existe uma negociação, uma lista de presentes que o noivo precisa entregar ao pai ou ao tio da noiva, incluindo multas para o caso de ter havido relação anteriormente ou gravidez, etc.

Pensando nos caminhos da estética cinematográfica dessa nova geração, Ondjaki cita Sérgio Afonso, um fotógrafo angolano, que está fazendo clipes e planejando entrar na seara de documentários, provavelmente no próximo ano. Afirma que Kiluanje tem uma estética própria, derivada do fato de ser Inês Gonçalves quem faz a direção fotográfica de todos os seus filmes, inclusive de Oxalá. Cita como exemplo as imagens paradas que aparecem no filme, como se fossem fotos, que seriam ideia dela. O realizador não identifica uma unidade estética em sua geração, apontando escolhas muito diferentes, como é o caso dos Assaltos em Luanda I, II e III, de Dito, alcunha de Henrique Narciso, uma trilogia de ficção que considera muito diferente, mas interessante de estudar. Outro filme citado foi Rostov em Luanda, de Abderrahmane Sissako, um outro estilo de documentário, mas que para o palestrante é muito bonito.

A seguir fala das dificuldades de editar a dois, pois as ideias não coincidiam totalmente. Ondjaki estava morando em Luanda, e Kiluanje morava fora da cidade há muitos anos, quando foi chamado pelo primeiro para fazer o filme. 
Portanto é normal que a visão dele sobre Luanda fosse diferente da minha. $\mathrm{E}$ as coisas que nós queríamos passar para fora, sobretudo para fora, eram muito diferentes. Porque quem tem o referencial de estar lá, e ouve aquela frase da irmã Domingas a dizer que as crianças estão muito violentas, partem uma garrafa e matam-se uma a outra, relativiza. Mas vocês aqui, ou alguém na Suécia vai pensar "meu Deus, não posso ir a Luanda, as crianças partem a garrafa e matam-se umas às outras!”. Mas aquela é uma frase da irmã Domingas, eu não posso mudar a frase dela. Ela quis dizer isso, tudo bem, mas passa uma impressão que não é real! As crianças não andam nas escolas, todas a matar-se umas às outras com cacos de garrafas! Ela pode ter visto isto, pois mora num bairro muito complicado. Mas mesmo no bairro dela, eu não acredito que todos os dias haja crianças feridas. Nós brincávamos na escola com armas, com pedras, e nos magoávamos. Mas não é partir a garrafa pra matar o colega! Esta frase eu tiraria, mas tenho que respeitar que são duas pessoas a fazer o filme, não é?

Outra coisa que ele aponta é para o fato de que o resultado final do filme nunca é aquilo que se planificou. Este foi o filme que foram obtendo, na medida em que foram filmando. E cita o exemplo da irmã Domingas, que conhecia lugares interessantes e os levava lá. Apenas os rappers aceitaram mostrar suas casas, ninguém mais. Só se pode editar o material obtido, não há como criar. Ondjaki admite que há em sua versão de Luanda uma certa parcialidade, porém não julga ser isso um problema. Para ele, o problema reside no fato de que Angola precisaria de muitos documentários por ano, não apenas um. É um documentário, feito por duas pessoas, editado de acordo com suas tendências pessoais e estéticas. "Um filme - não pretendemos com isto dizer que Luanda é assim, isto é que é a verdade! Não, isto é uma pequena fotografia sobre um universo em que procuramos misturar dez pessoas distintas. Mas na verdade o que tem que se fazer são outros filmes."

Segundo sua opinião não existem mais produções pela dificuldade de se produzir sem financiamentos oficiais. Oxalá cresçam pitangas foi realizado pelos três, apenas: ele, Kiluanje e Inês Gonçalves, ${ }^{15}$ onde faziam o papel de produtores, presidentes, motoristas, diretores, etc.

15 Inês Gonçalves nasceu em Málaga. Entre 1984 e 1986 frequentou o Photographic Training Centre, em Londres; trabalhou como fotógrafa para o semanário $O$ Independente. Foi editora de fotografia da revista Kapa. Expôs em 1992 no Círculo de Bellas Artes de Madrid; em 1994 no Festival Internacional de Fotografia de Moda de Paris; em 1996 nos Encontros de Fotografia de Coimbra, entre outros. 
Quanto à questão da participação do Estado, o diretor explica que este tem apoiado a indústria cinematográfica através de institutos, mas que existem muitas dificuldades. A distribuição é um dos aspectos mais complicados da pós-produção de um filme, no seu entender. Em sua experiência pessoal, a filmagem em si não apresentou grandes problemas, foi possível fazer. Também foi feita uma cópia, em Digital Betacam, ${ }^{16}$ que foi enviada para Rádio e Televisão de Portugal (RTP), para a Televisão Pública de Angola (TPA) e para o Canal Arte, da França. No entanto, esse formato não é comercializável, é preciso transformá-lo em DVD. Segundo ele, aqui começam os problemas mais sérios, pois não há uma empresa ou produtora que faça esse trabalho mais ainda, que se dedique à distribuição desse material. E mais, em Luanda não existem lojas especializadas em venda de DVDs, os filmes aparecem na rua, vendidos nos sinais. Assim, muita coisa que é produzida por esses jovens não chega sequer ao conhecimento do grande público.

Até tem havido agora [produções de filmes], só que não chegam a lado nenhum. Outro dia estava a falar com o Mário Bastos, lá em Luanda, a dizer que nós temos que catalogar isto! Temos que fazer um blog, um site, qualquer coisa, mesmo que a gente não tenha o filme, para constar: existe o filme tal, no musseque tal, ano tal, com tantos minutos. Ao menos para catalogar, porque senão ninguém sabe que estes filmes existem! Sabe só o rapaz lá do bairro dele, e ninguém mais sabe. Se tu estás aqui a fazer uma pesquisa, não vais saber qual o filme, mas ao menos que fizeram um filme em tal lugar, tal época, sobre tal assunto, isto é importante! Agora, penso que a distribuição ainda vai demorar.

Nessa etapa de nossa pesquisa procuramos nos focar mais nas ideias e planejamentos iniciais, do que no filme propriamente dito, pois como o autor mesmo diz, "outra coisa que acontece, e quem escreve roteiros sabe disso, é que o filme que se obtém nunca é aquilo que se planifica”. Na verdade, os erros, o acaso, a própria natureza do filme, que é um documentário, permitiu certa liberdade de expressão aos seus personagens que não pôde e nem deveria ser direcionada pelos autores. Kiluanje e Ondjaki tiveram muita sabedoria e sensibilidade ao conduzir o resultado em função do que foi se obtendo. No depoimento pudemos ouvir do autor a razão das suas escolhas,

16 Formato de vídeo profissional. 
os conflitos e as dúvidas entre os produtores. Algumas vezes, muito mais do que esclarecer, ele enriqueceu e acrescentou dados ao que é visto na tela; outras, no entanto, nos mostrou como nem sempre o resultado final condiz com a intenção dos autores. Evidentes foram as diferenças de alcance entre a palavra dita e o suporte audiovisual, entre o discurso oral do cineasta e sua tradução em fotogramas e trilha sonora. Se uma imagem, mesmo acrescida de áudio, jamais dará conta plenamente de uma palavra, o oposto é igualmente verdadeiro. É nesse sentido que acreditamos ter sido extremamente enriquecedor para nosso trabalho a utilização do depoimento oral, colocando-o em diálogo com o discurso audiovisual.

\section{Referências}

AMADO, J.; FERREIRA, M. de M. (Coord.). Usos e abusos da história oral. Rio de Janeiro: Fundação Getúlio Vargas, 1996.

OXALÁ CRESÇAM PITANGAS - histórias de Luanda. Direção e realização: Ondjaki e Kiluane Liberdade. Angola e Portugal, 2006. 62 min. DVD.

TOURTIER-BONAZZI, C. de. Arquivos: propostas metodológicas. In: AMADO, J.; FERREIRA, M. de M. (Org.). Usos e abusos da história oral. Rio de Janeiro: Editora da Fundação Getúlio Vargas, 1996. p. 233-246.

Resumo: Neste artigo interpretamos a palestra ministrada por Ondjaki e seguida de debate, ocorrida no dia 21 de novembro de 2011 (Afrocine/LeÁfrica/IH/UFRJ), após a apresentação do filme Oxalá cresçam pitangas - histórias de Luanda (2006), produzido e realizado por este cineasta e Kiluanje Liberdade. A transcrição buscou não perder nada do que pudesse ser compreendido nos silêncios, ênfases ou reticências, e para tanto foram usados recursos gráficos, como o negrito, itálico ou parênteses. A seguir, o texto foi enviado para o autor, para que este retificasse aquilo que sentisse necessário, assim como autorizasse a sua utilização em nossa atual investigação. Nosso objetivo inicial foi precisar o lugar de produção da obra, comparar as intenções do autor com o produto realizado, e, através da elaboração de uma nova fonte primária, alargar as dimensões de nosso objeto de estudo.

Palavras-chave: Angola, cinema, discurso oral.

Film in debate: Ondjaki speaks of his work Oxalá cresçam pitangas

Abstract: The object of analyses of this article is the Ondjaki's lecture, that took place in November 21(Afrocine/LeÁfrica/IH/ UFRJ), about Oxalá cresçam pitangas - histórias de 
Luanda (2006), a movie produced and directed by Kiluanje Liberdade. The transcription was made in order not to lose any of what could be understood in silence, emphasis and ellipsis. Therefore, graffic resources such as bold, italic and parentheses were used. The text was sent to the author, so he could make the adjustments he though it could be necessary, well as give the authorization needed to utilize his words in this work. The main objective of this work was to point out the location the movie took place in, to compare the author's idea with the project accomplished and, through the elaboration of a new primary-source, to expand the dimensions of our object of study.

Keywords: Angola, cinema, oral speech.

Recebido em 27/08/2012

Aprovado em 20/10/2012

Um trailer do filme comentado no artigo pode ser visto em: http://www.youtube.com/watch?v=17BJfqWfm3c 